\title{
MIS Approach FOR Diverticula of the Esophagus
}

\author{
T. Laubert ${ }^{1}$, P. Hildebrand ${ }^{1}$, U. J. Roblick ${ }^{1}$, M. Kraus ${ }^{1}$, H. Esnaashari ${ }^{1}$, P. Wellhöner ${ }^{2}$, H. P. Bruch ${ }^{1}$ \\ ${ }^{1}$ Department of Surgery, University of Schleswig-Holstein, Campus Lübeck, Lübeck, Germany, \\ ${ }^{2}$ Department of Medicine I, University of Schleswig-Holstein, Campus Lübeck, Lübeck, Germany
}

\begin{abstract}
Purpose: Diverticula of the esophagus represent a rare pathological entity. Distinct classifications of the disease imply different surgical concepts. Surgery should be reserved for symptomatic patients only. Minimally invasive surgery (MIS) for treatment of esophageal diverticula encompasses rigid and flexible intraluminal endoscopy, thoracoscopy and laparoscopy. We here give an overview on the pathogenesis of esophageal diverticula, the minimally invasive surgical techniques for treatment and the recent literature. Additionally, we present our own experience with MIS for midthoracic diverticula.

Methods: We analyzed the cases of patients who underwent MIS for midthoracic diverticula with regard to preoperative symptoms, perioperative and followup data.

Results: Three patients (two female, one male, age 79, 78 and 59 years) received thoracoscopic surgery for midthoracic diverticula. All patients reported of dysphagia and regurgitation. In two patients $\mathrm{pH}$-investigation showed pathological reflux but manometry was normal in all patients. Operating time was 205, 135 and 141 minutes. We performed intraoperative intraluminal endoscopy in all patients. There were no intraoperative complications and although no surgical complications occured postoperatively one patient developed pneumonia which advanced to sepsis and lethal multi organ failure. Upon follow-up the two patients did not have recurrent diverticula or a recurrence of previous symptoms.

Conclusions: Surgery for diverticular disease of the esophagus has been associated with high rates of morbidity and mortality. Despite the lethal non-surgical complication we encountered, with regard to recent publications minimally invasive apporaches to treat patients with symptomatic esophageal diverticula entail lower rates of complications with better long term results in comparison to open surgery.
\end{abstract}

Key words: esophagus, diverticula, minimally invasive surgery, diverticulectomy, follow-up

\section{INTRODUCTION}

Diverticula of the esophagus represent a benign esophageal disorder. The reported prevalence ranges between $0.015 \%$ and $2 \%$ but only seldom they become symptomatic and thus apparent [1,2]. Esophageal diverticula are usually single but are also reported to oc- cur synchronously in up to $25 \%$ [3]. Different locations with distinct pathopyhsiological mechanisms in their occurrence imply different techniques of therapeutic strategies. Generally, surgery should be reserved for symptomatic patients only. Technological advances and research in laparoscopic and thoracoscopic surgery expanded the applicability of minimally invasive operations to many general and visceral surgery procedures. By now, thoracoscopic, laparoscopic and endoscopic approaches for diverticulectomy have been established [4-6]. In many situations, rendez-vous procedures, i.e. the combination of endoscopy and thoraco-/laparoscopy appear favourable and result in good functional outcomes. However, due to the rare occurrence of esophageal diverticula prospective randomized trials to systematically analyze different surgical concepts have not been set up and most data available is based on retrospective evaluation of peri- and postoperative data $[7,8]$. We here present the perioperative data and follow-up results of three patients treated at our centre by minimally invasive surgery for midthoracic diverticula and give an overview of the current literature regarding this topic. We briefly describe technical aspects of minimally invasive resection of Zenker's diverticula and review recent data on this particular topic.

\section{AnATOMY, PATHOPHYSIOLOGY AND ASSESSMENT}

The anatomy, etiology and symptoms of esophageal diverticula have prompted two separate classifications which reflect location of the diverticula on the one and pathogenetic mechanisms leading to diverticula formation on the other hand. Predominant locations are directly above the upper esophageal sphincter as first anatomically correctly described by Zenker [9], parabronchially (midthoracic) and above the lower esophageal sphincter (epiphrenic). Both Zenker's and epiphrenic diverticula are false diverticula with the mucosal layer protruding through gaps in the outer muscular layer and are thus considered pulsion diverticula. The underlying mechanism in both cases is an abnormal motility of the esophagus with an impaired relaxation of the sphincter while propulsive contractions continue. Evidently, this leads to an increased intraluminal pressure just above the sphincters which then causes the mucosal layer to develop a pouch pushing through weakened sites of the muscular wall [3, 10-12]. Consequently, the surgical treatment for these divertic- 
ula consists of both a myotomy of the according sphincter and a resection of the diverticulum.

Traction diverticula are rare and mostly result from scarring following an inflammation predominantly occurring in the mediastinal lymph nodes. They were more common throughout periods where tuberculosis was more frequent [10]. In traction diverticula, the entire esophageal wall is affected creating a true diverticulum. However, studies demonstrated that many midthoracic diverticula are also associated with motility abnormalities such as spasm, achalasia or hypertension of the lower esophageal sphincter [13, 14].

With $80-90 \%$ the predominant symptom of esophageal diverticula is dysphagia [15]. Regurgitation, recurrent chest pain and heartburn are also common [6]. Additionally, a Zenker's diverticle can cause localised swelling of the neck and a pressure like feeling [15]. Many patients describe a typical history of aspiration which mainly occurs during nights.

Patients with symptoms suggestive for an esophageal diverticulum should undergo radiological, endoscopic and functional studies to verify the existence of a diverticulum, determine its location, rule out differential diagnoses and assess the extend of functional disorder. A barium swallow shows the location and size of a diverticulum with great accuracy and sensitivity (Fig. 1) [16]. Endoscopy rules out other pathologies, most importantly malignancy and additional in-
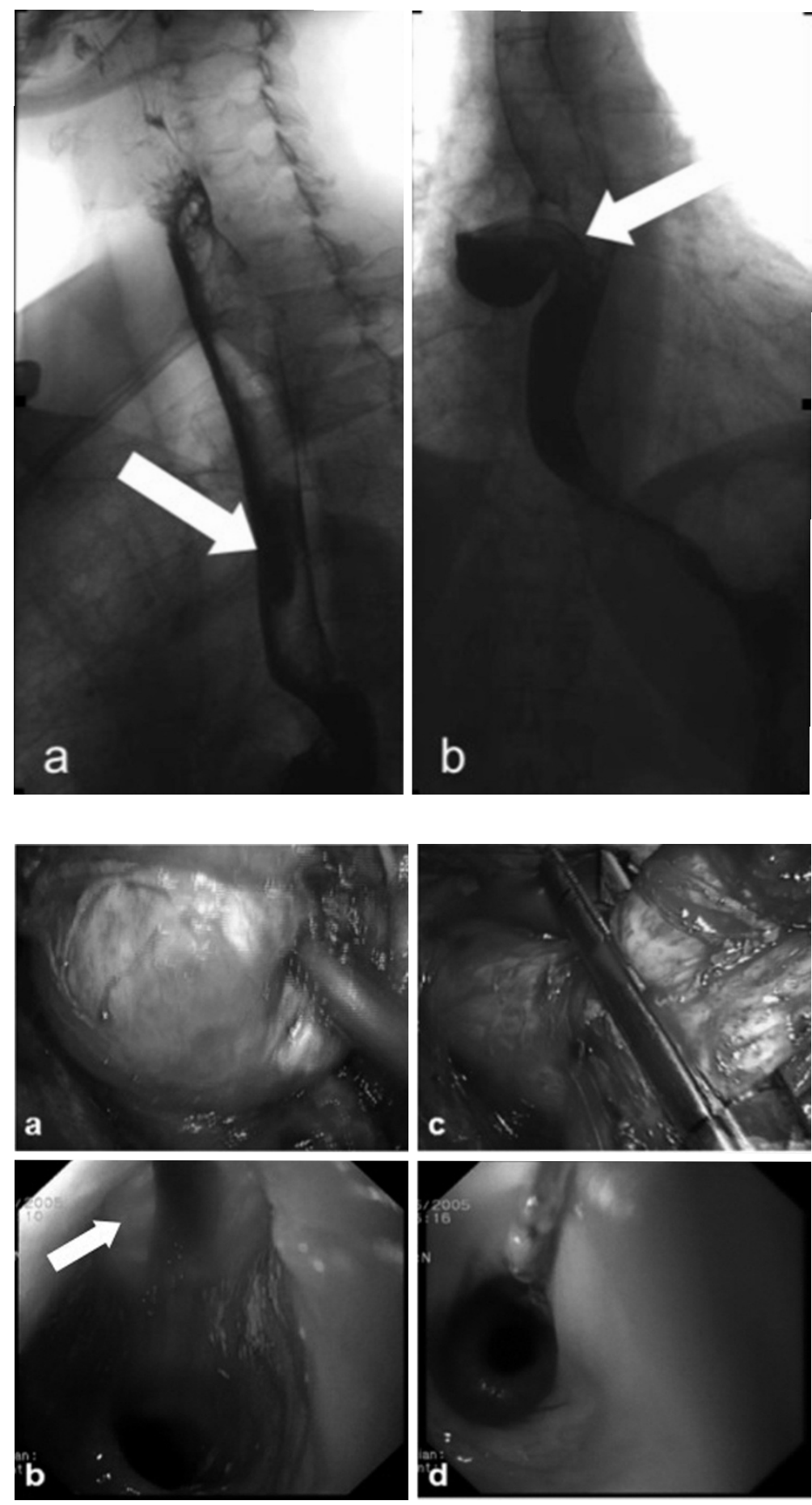

Fig. 1. Barium swallow of a patient with a peribronchial diverticulum (Patient No. 3) a) in a.p. view and $b$ ) in lateral view.
Fig. 2. Thoracoscopic resection of a parabronchial diverticulum (Patient No. 1) a) exposure of the neck of the diverticulum, b) intraluminal view with the light source of the camera $(\ddagger)$ within the thorax shining through the esophageal wall, c) application of the linear stapler at the neck of the diverticle, d) intraluminal control of the stapling line. 

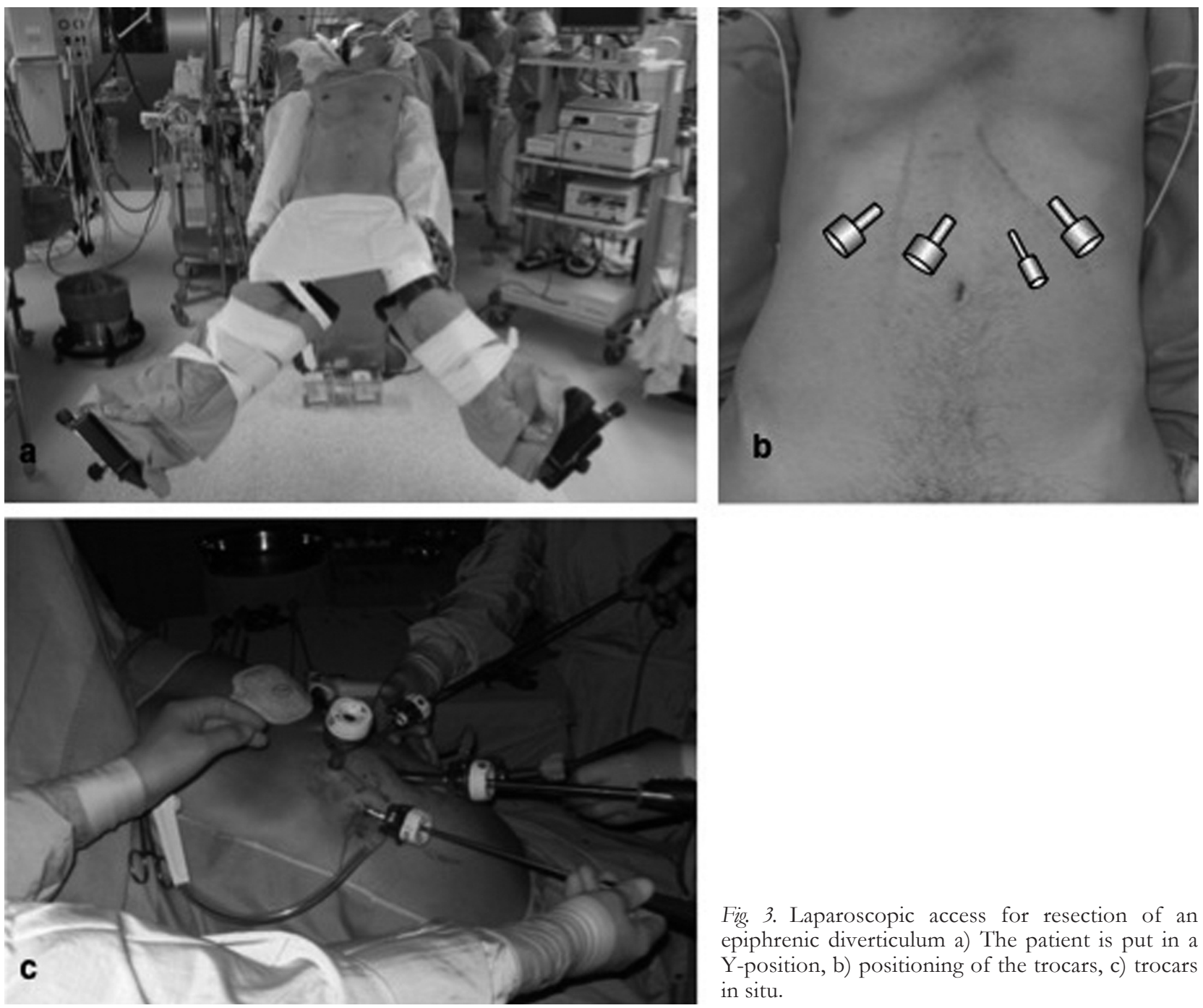

Fig. 3. Laparoscopic access for resection of an epiphrenic diverticulum a) The patient is put in a Y-position, b) positioning of the trocars, c) trocars in situ.

formation such as diameter of the diverticulum's neck can be received. Furthermore, endoscopy can often distinguish obstructive from functional disorders.

Esophageal manometry reveals functional disorders that either prompt the development of an esophageal diverticle or are associated with its existence. We routinely perform manometric measurements to determine the extend of the underlying muscular dysfunction which has direct impact on the surgical procedure. A $24 \mathrm{~h}$ monitoring of $\mathrm{pH}$ should be performed to profile gastroesophageal reflux although only a minority of the patients with an epiphrenic diverticle who complain of heartburns seem to have a pathological pH-test [6].

Minimally InVAsive APPROACH FOR TrEATMENT OF ZENKER's DiVERTICULA

The clear exposure of the diverticle's neck allows a safe and efficient resection but dividing the cricopharyngeus muscle fibres also constitutes a crucial step in the treatment of a Zenker's diverticle. The endoluminal approach using rigid laryngoscopes has become the predominant surgical technique [3]. Minimally invasive endoluminal approaches encompass both endoscopic stapling of the esophageal wall and fibre-op- tic treatment. Both techniques imply a diverticulostomy together with a myotomy. Using an endostapler it is possible to dissect the septum between the lumen of the esophagus and the diverticle. Simultaneously, the anterior wall of the diverticulum and the posterior wall of the esophagus are sealed with a double stapling line. Other principle techniques to dissect the septum are needle-knife incision [17], argon plasma coagulation [18] (Fig. 4) and monopolar coagulation [19]. Usually, to complete the diverticulostomy requires two to five sessions according to size of the diverticulum. There are no randomized trials comparing the different approaches and the endoscopist's choice of technique is based upon experience and preference.

Clinical resolution rates appear satisfactory with 84$100 \%[20,21]$ although in a study of 31 patients the recurrence rate was $35 \%$ [20].

\section{EXPERIENCE AT OUR OWN INSTITUTION}

We retrospectively analyzed preoperative symptoms and perioperative data of three patients who underwent minimally invasive surgery for midthoracic diverticula. Perioparative data included type of surgery, time needed for the procedure, intraoperative and 

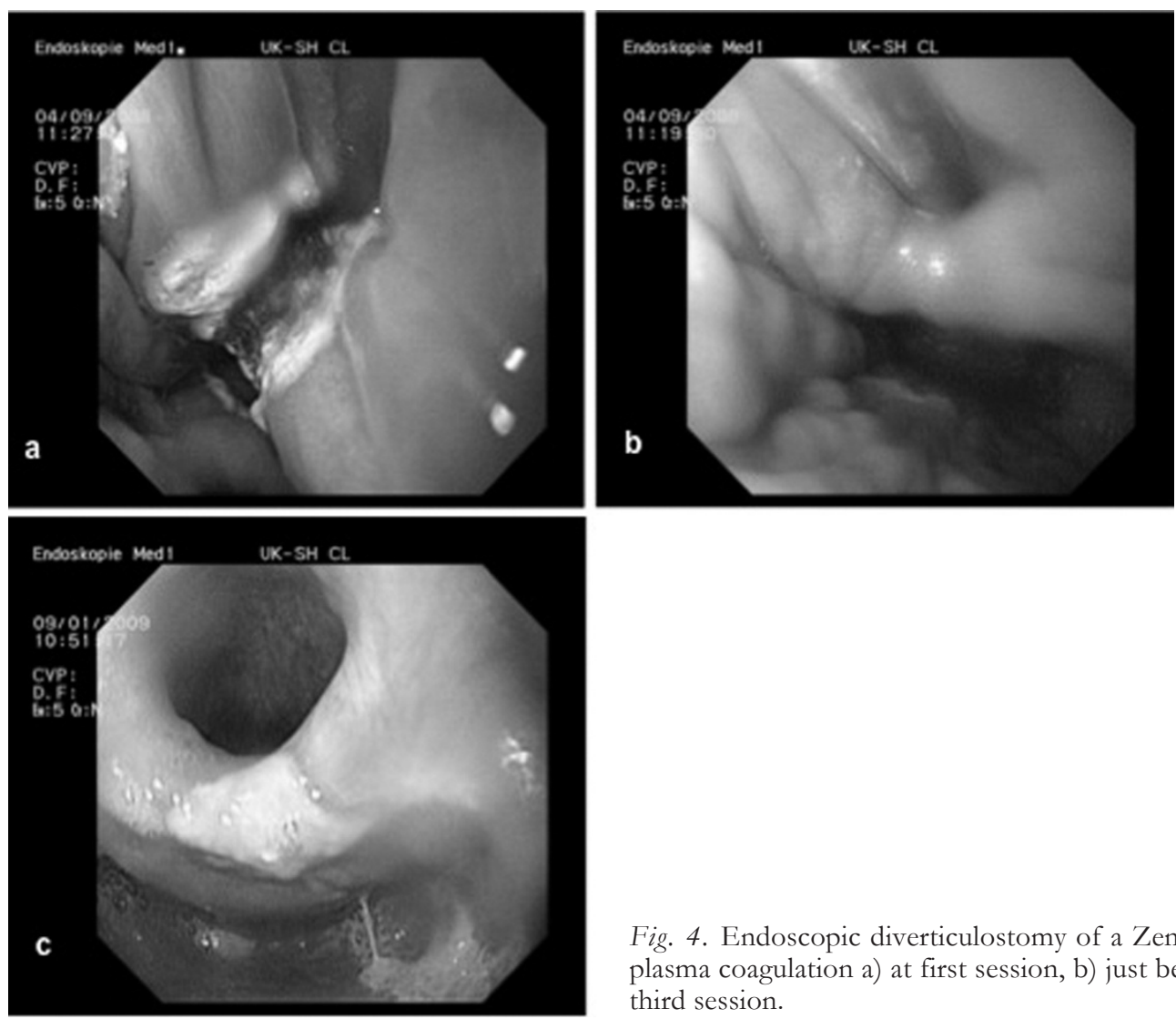

Fig. 4. Endoscopic diverticulostomy of a Zenker-diverticulum with argon plasma coagulation a) at first session, b) just before second session, c) after third session.

postoperative complications, time until first oral intake and length of hospital stay. Complications were considered minor in cases where no surgical or endoscopic re-intervention was necessary. Complications were considered major if patients had to undergo surgical or endoscopic re-intervention. Follow-up was done by performing telephone interviews with focus set on persistence, recurrence or absence of preoperatively recorded symptoms.

\section{SurgicAl TECHNiQue FOr MidTHORACIC DIVERTICULA}

The patient is put in a prone position. Surgical access is performed from the patient's right hand side. The use of a double lumen tubus allows a collapse of the right lung which facilitates the procedure. The esophagus is mobilized dorsally taking care not to injure the azygos vein, the bronchial system or the descending aorta. If necessary, small arterial vessels from the aorta to the esophagus are clipped. The neck of the diverticulum has to be fully exposed (Fig. 2a, b). The dissection and simultaneous closure of the midthoracic pouch is achieved by using an endostapler (Fig. 2c). The perfect alignment of the stapler to the longitudinal axis of the esophagus and the complete resection of the diverticulum is verified by endoscopic control. As most midthoracic diverticula are true diverticula, the endostapler closes the esophageal wall in its full thickness. For safety reasons, adding single sutures that grasp the esophageal wall laterally of the closed resection-line are performed to cover the stapler-line. Care is taken not to create a stenosis of the esophagus when applying these extra sutures and this step should also be carried out under endoscopic intraluminal vision (Fig. 2d). Two chest tubes are placed apically and basally. We perform a barium-swallow three days postoperatively before the patient is started on oral intake.

\section{SurgicAl TECHNIQUE FOR EPIPHRENIC DIVERTICULA}

The position of the patient is equal to the one used in other minimally invasive operations of the stomach and the distal esophagus e. g. fundoplication (Fig. 3). We use four trocars. The surgeon stands between the patient's legs, the first assistant on the patient's left and a second assistant on the patient's right hand side. First, the diaphragmatic crura are exposed. The esophagus is then isolated in its distal segment and mobilized in the caudal part of the mediastinum. We use Harmonic ${ }^{\circledR}$ scalpel for dissection. Ideally, the pleural cavity is not affected during preparation. Under intraluminal endoscopic control the diverticle is identified and its neck isolated. Using a linear endostapler the neck of the diverticle is dissected and closed simultaneously with care taken to line up the stapler exactly parallel to the longitudinal axis of the esophagus. The stapler line is protected by approximating the muscular edges of the diverticular gap with single sutures. With the hydro-pneumatic test we verify a sufficient closure. We perform myotomy reaching from $2 \mathrm{~cm}$ distally of the cardia to $5-6 \mathrm{~cm}$ above the neck of the diverticle. For anti-reflux we then finish the operation with a $360^{\circ}$-Nissen-fundoplication. We perform a bariumswallow five days postoperatively before the patient is started on oral intake. 


\section{RESULTS}

Patient No. 1. This 79 year old female patient had a history of recurrent dysphagia and reported of regurgitation. An Esophago-gastro-duodenoscopy showed a midthoracic diverticle with residues of oral intake and a soor esophagitis. After antimycotic treatment a repeated endoscopy showed no signs of esophagitis. A $\mathrm{pH}$-test and a manometric investigation did not show any abnormalities and the patient was scheduled for surgery. Through a thoracoscopic approach we perfomed the resection of the diverticle in the above mentioned technique. An intraoperative esophagoscopy ensured correct positioning of the endostapler. There were no intraoperative complications. Operation time was 205 minutes. There were no postoperative complications. First intake of fluids was on day four post surgery, first intake of solid food on day seven. Due to a prolonged secretion the thoracic drains were removed on day five. The patient was discharged on day 14. Eighteen months after surgery the patient had no complaints. There were no symptoms of either stenosis or recurrent regurgitation.

Patient No. 2. Reporting of severe dysphagia and intermittend regurgitation this 78 year old female was diagnosed with a midthoracic diverticle of the esophagus. PH-investigation showed minor pathological reflux throughout nightly periods, manometry did not show any abnormalities. We performed thoracoscopic resection of the diverticle under esophagoscopic vision (Figure 2) and placed additional sutures to cover the staple line. There were no intraoperative and no surgical complications. Operating time was $135 \mathrm{~min}-$ utes. A barium contrast swallow on day 4 did not show any leakage and the patient received oral fluids. First intake of solid food was on day 8. On day 7 the patient acquired pneumonia which on day 16 advanced to sepsis and multiorgan failure consecutively. Autopsy showed an intact suture line at the esophagus.

Patient No. 3. This 59 year old male presented with intermittent dysphagia and reported some events of regurgitation at nighttime. A barium swallow showed a midthoracic diverticle (Fig. 1). Esophago-gastroduodenoscopy verified a midthoracic diverticle with mild inflammation. PH-metry showed pathological nightly reflux but manometry was normal. We perfomed a thoracoscopic resection of the diverticle under esophagoscopic vision. Operating time was 141 minutes. Neither intraoperative nor perioperative complications occurred. Barium swallow on day three after surgery did not show any abnormalities and the patient was started on oral fluids the following day. First intake of solid food was on day 7 and the patient was discharged on day 10. Upon follow-up 34 months postoperatively the patient reported of minor episodes of heartburn which could be well controlled medically. A repeated esophago-gastro-duodenoscopy showed minor signs of reflux, but no recurrence of the diverticle or stenosis was diagnosed.
The indication for a surgical intervention in patients with esophageal diverticula is mainly based on symptoms. Mere gastroesophageal reflux justifies a pharmacological approach whereas recurrent aspiration clearly constitutes an indication for an invasive procedure. Due to its location above the upper esophageal sphincter, Zenker's diverticula tend to be symptomatic more often than epiphrenic diverticula. Parabronchial diverticula are rarely symptomatic.

For treatment of epiphrenic diverticula some authors described the mere resection of the diverticle without myotomy as a sufficient therapy which produced unsatisfactory results [22]. There is an ongoing debate about the appropriate extend of the myotomy. It has been attempted to minimize the myotomy by correlating it with the manometric findings [23] but esophageal motility disorders may only occur intermittently and with a certain range of intensity which makes this approach problematic. Based on their investigations of functional abnormalities in 23 patients with epiphrenic diverticula D'Journo et al. concluded that a long myotomy including the lower esophageal sphincter relieved functional obstruction and symptoms but partial fundoplicatio could not prevent reflux damage to the esophageal mucosa [12].

Advantages of minimally invasive approaches in general have been demonstrated in several studies. Especially for interventions of the esophagus including resections for malignant disease studies showed a significantly lower rate of lung infections, a lower rate of overall complications and a shorter length of hospital stay [24].

Surgical therapy for either parabronchial or epiphrenic diverticula has been associated with a considerable rate of morbidity and mortality due to the advanced age of the patients, the intraoperative deflation of the right lung, overseen leaks at he site of the resection and postoperative recurrence of symptoms. Due to the rare incidence of esophageal diverticula no randomized trials have been put forward to directly compare a laparoscopic approach to the standard operation via thoracotomy and laparotomy, respectively.

Kilic et al. stated that a minimally invasive operation entails a lower mortality rate which in their analysed series of minimally invasive procedures was $1.2 \%$ as opposed to $6.1 \%$ in the analyzed open series [25]. Looking at the individual studies mortality has been reported to be as high as $11 \%$ in open [14] and $7 \%$ in laparoscopic resections [26].

Certainly, with three patients our own series is too small to state a reliable mortality rate. The one patient died due to a lung infection which constitutes the most common lethal complication in patients undergoing esophageal surgery. However, it has been shown that minimally invasive approaches to the esophagus entail pulmonary complications less frequently than open operations [24].

There were no major complications in the study published by Palanivelu et al. [27] whereas other studies stated rates of reoperation for complications in as much as $17 \%$ [28] and 20\% [29]. The largest study of minimally invasive operations published to date en- 
compassed 20 patients among which there were 4 midthoracic diverticula. They reported an overall complicaton rate of $45 \%$ including four leakages and one intraoperative perforation [7]. A different study of six patients described an overall complication rate of 50\% with one intraoperative perforation [28]. Rates for postoperative leakages vary between $0 \%$ [27] and 33\% [30]. Within a total of 10 different retrospective studies covering 92 patients there occurred 12 leakages $(13.0 \%)$ [25]. In our series we did not have to convert to open surgery and did not experience any intaraoperative or postoperative surgical complications.

Our patients did not have recurrent forming of an esophageal diverticle and they were asymptomatic upon follow-up. This is in line with other studies of minimally invasive approaches which in minimum showed a rate of $83 \%$ for improvement of symptoms [27]. In most other studies the rate of significantly improved symptoms was $100 \%[6,26,28]$. The few studies that looked at recurrence reported rates of $0 \%[7$, $26]$ and $20 \%$, respectively [29]. Series looking at open surgery showed success rates between $76 \%$ in a study covering 35 patients [23] and $94 \%$ in a study with 18 patients [11]. Most analyses encompass both patients with epiphrenic and midthoracic diverticula which makes a comparison of data difficult.

\section{CONCLUSION}

Surgery for diverticular disease of the esophagus has been associated with high rates of morbidity and mortality. Therefore, indication for surgery should be stated carefully. Based on both data from the literature and our own experience we believe that minimally invasive apporaches to treat patients with a symptomatic esophageal diverticle entail lower rates of complications with better long term results regarding recurrence of symptoms given the patients are treated at a center with the required expertise in the field of minimally invasive operations, interventions of the esophagus especially. Since the pathology of midthoracic and epiphrenic esophageal diverticula is rare it seems questionable whether we will ever be able to implement prospective studies with a sufficient number of patients or whether we will have to rely on results from retrospective investigations.

\section{REFERENCES}

1. Wheeler D. Diverticula of the foregut. Radiology 1947, 49:476-481

2. Schima W, Schober E, Stacher G, Franz P, Uranitsch K, Pokieser P, Wenzl E, Resch A, Herold CJ. Association of midoesophageal diverticula with oesophageal motor disorders. Videofluoroscopy and manometry. Acta Radiol 1997, 38:108-114.

3. Costantini M, Zaniotto G, Rizetto C, Narne S, Ancona E. Oesophageal diverticula. Best Pract Res Clin Gastroenterol 2004, 18:3-17

4. Hillel AT, Flint PW. Evolution of Ensoscopic Surgical Therapy for Zenker's Diverticulum. Laryngoscope 2009, 119:39-44

5. Palanivelu C, Rangarajan M, Senthilkumar R, Velusamy M. Combined thoracoscopic an endoscopic management of mid-esophageal benign lesions: use of the prone position. Surg Endosc 2008, 22:250-254
6, Tedesco P, Fisichella PM, Way LW, Patti MG. Cause and treatment of epiphrenic diverticula. Am J Surg 2005, 190:891-894

7. Fernando HC, Luketich JD, Samphire J, Alvelo-Rivera M, Christie NA, Percival OB, Landreneau RJ. Minimally invasive operation for esophageal diverticula. Ann Thorac Surg 2005, 80:2076-2081

8. Eubanks TR, Pellegrini CA. Minimally invasive treatment of esophageal diverticula. Semin Thorac Cardiovasc Surg 1999, 11:363-367

9. Zenker FA, von Ziemsen H. Krankheiten des Ösophagus. In: Handbuch der Speciellen Pathologie und Therapie, Vol. 7 (Suppl.). FCW Vogel, Leipzig 1877, pp 1-87

10. Thomas ML, Anthony AA, Fosh BG, Finch JG, Maddern GJ. Oesophageal diverticula. Br J Surg 2001, 88:629-642

11. Nehra D, Reginald V, DeMeester T, Theisen J, Peters JH, Crookes PF, Bremner DG. Physiologic basis for the treatment fo epiphrenic diverticulum. Ann Srug 2002, 235:346-354

12. D'Journo XB, Ferraro P, Martin J, Chen LQ, Duranceau A. Lower oesophageal sphincter dysfunction is part of the functional abnormality in epiphrenic diverticulum. Br J Surg 2009, 96:892-900

13. D’Ugo D, Cardilo G, Granone P, Coppola R, Margaritora S, Picciochi A. Esophageal diverticual. Physipathological basis for surgical management. Eur J Cardiothorac Surg 1992, 6:330-334

14. Fekete R, Vonns C. Surgical management of esophageal thoracic diverticula. Hepatogastroenterology 1992, 39:9799

15. Ferreira LEVVC, Simmons DT, Baron TH. Zenker's diverticula: pathophysiology, clinical presentation, and flexible endoscopic management. Dis Esophagus 2008 21: 1-8

16. Hansmann J, Grenacher L. Radiologische Bildgebung des oberen Gastrointestinaltrakts Teil I: Ösophagus. Radiologie 2006, 46:1077-1088

17. Costamagna G, Iacopini F, Tringali A, Marchese M, Spada C, Familiari P, Mutignani M, Bella A. Flexible endoscopic Zenker's diverticulotomy: cap-assisted technique vs. Diverticuloscope-assisted techique. Endoscopy 2007, 39:146-152

18. Rabenstein T, May A, Michel J, Manner H, Pech O, Gossner L, Ell C. Argon plasma coagulation for flexible endoscopic Zenker's diverticulotomy. Endoscopy 2007, 39:141-145

19. Christiaens P, DeRoock W, Van Olmen A, Moons V, D'Haens G. Treatment of Zenker's diverticulum through a flexible endoscope with a transparent oblique-end hood attached to the Tipp and a monopolar forceps. Endoscopy 2007, 39:137-140

20. Vogelsang A, Preiss C, Neuhaus H, Schumacher B. Endotherapy of Zenker's diverticulum using the needleknife techique: long-term follow-up. Endoscopy 2007, 39:131-136

21. Sakai P, Ishioka S, Maluf-Filho F, Chaves D, Moura EG. Endoscopic treatment of Zenker's diverticulum with an oblique-end hood attached to the endoscope. Gastrointest Endosc 2001, 54:760-763

22. Harrington SW. The surgical treatment of pulsion diverticula of the thoracic oesophagus. Ann Surg 1949, 129:606-618

23. Varghese TK, Marschall B, Chang A, Pickens A, Lau CL, Orringer MB. Surgical treatment of epiphrenic diverticula: a 30-year experience. Ann Thorac Surg 2007, 84:18011809

24. Verhage RJJ, Hazebroek EJ, Boone J, Van Hillegersberg R. Minimally invasive surgery compared to open procedures in esophagectomy for cancer: a systematic review of the literature. Minerva Chir 2009, 64:135-146 
25. Kilic A, Schubert MJ, Awais O, Luketich JS, Landreneau RJ. Surgical management of epiphrenic diverticula in the minimally invasive era. JSLS 2009, 13:160-164

26. Del Genio A, Rossetti G, Maffetton V, Renzi A, Brusciano L, Limongelli P, Cuttitta D, Russo G, Del Genio G. Laparoscopic approach in the treatment of epiphrenic diverticula: long-term results. Surg Endosc 2004, 18:741745

27. Palanivelu C, Rangarajan M, Maheshkumaar GS, Senthilkumar R. Minimally invasive surgery combined with peroperative endoscopy for symptomatic middle an lower esophagea diverticula - a single institute's experience. Surg Laparosc Endosc Percutan Tech 2007, 18:133138

28. Fraiji E, Bloomston M, Carey L, Zervos E, Goldin S, Banasiak M, Wallace M, Rosemurgy AS. Laparoscopic management of symptomatic achalasia associated with epiphrenic diverticulum. Surg Endosc 2003, 17:160-1603

29. Van der Peet DL, Klinkenbert-Knol EC, Berends FJ, Cuesta MA. Epiphrenic diverticula: minimal invasive approach and repair in five patients. Dis Esophagus 2001, 14:60-62
30. Neoral C, Aujesky R, Bohanes T, Klein J, Král V. Laparoscopic transhiatal resection of epiphrenic diverticulum. Dis Esophagus 2002, 15:323-325

Received: February 2, 23010 / Accepted: February 18, 2010

Address for correspondence:

Dr. med. Tilman Laubert

Department of Surgery

University of Schleswig-Holstein, Campus Lübeck

Ratzeburger Allee 160

23552 Lübeck

Germany

Phone: +49-(0)451-500 2675

Fax: +49-(0)451-500 2069

E-mail: tlaubert@googlemail.com 